\title{
Researches on Roughness for the Main Brands of Dental Implants
}

\author{
Maria STOICĂNESCU \\ Transilvania University of Brasov, Romania, stoican.m@unitbv.ro \\ Dragoș BUDEI \\ Dentix Millennium SRL, Săbăreni, Giurgiu, Romania, budei.dragos@dentixmillennium.ro \\ Eliza BUZAMET \\ Dentix Millennium SRL, Săbăreni, Giurgiu, Romania, eliza.buzamet@gmail.com \\ Roxana BUDEI \\ Dentix Millennium SRL, Săbăreni, Giurgiu, Romania, roxanabudei@yahoo.com
}

\begin{abstract}
Main brands of dental implants demonstrate superior features confirmed for years now. Among them, specific mechanical properties of materials that dental implants are made of, and mechanical properties of the parts themselves, are together with surface treatments, the most important traits that stay behind their success. The comparison of the main brands of dental implants, was made by means of objective analysis (roughness measurement, SEM microscopy with identifying chemical composition, tear tests, etc.). The study tried to penetrate into the depth of crystal structures and chemical formula behind good behaviour that was demonstrated in clinical applications. The study demonstrates the diversity of titanium alloys used in the production of dental implants and opens opportunities of new formulas. New proportions between the percentages of aluminium or titanium and vanadium, and other elements use (zirconium, niobium, etc.), will make possible to obtain new implants with superior performance.
\end{abstract}

\section{Keywords}

roughness, dental implants, titanium alloy

\section{Introduction}

Worldwide, the use of dental implants in the current therapist practice has made a huge difference. The appearance of a large number of manufacturers of dental implants has increased the competition and this has implicitly led to an increase in the variety of implants, both constructively, and of the materials used, each manufacturer looking for the best ways to differentiate himself from other manufacturers. The major dental implant companies have very strong Research \& Development departments. All manufacturers aim to achieve better biocompatibility and a longer period of use of dental implants. The biocompatibility of an implant depends on a number of extrinsic factors such as: patient's clinical picture, general health status, age, tissue permeability, immunological factors, lifestyle (smoking), but also intrinsic factors of the implant: type of material used, internal and external architecture, surface properties (treatments, material roughness, chemical reactivity, corrosion behaviour), porosity and uniformity of the material, its toxicity, and last but not least mechanical characteristics [2, 3]

Practically every implant has its own characteristics that distinguish it from the others characteristics, that dictate its biological reactivity, distinction making the chemical and morphological characteristics of the implant surface $[1,4]$.

Unfortunately, there is still no international standard impose of specific conditions of quality that all implants on the market to fulfil. In this situation, dentists currently have limited information, often with greater marketing value than scientifically, when choosing their dental implant system, although they thus assume responsibility for the use of that implant in patients.

The purpose of this paper is to make a comparative study of mechanical characteristics, namely roughness, for the main types of dental implants present on the market today. 


\section{Materials and Methods}

In the aim of this study, were used 11 types of implant (Table 1), which were purchased from the market, testing being performed on them to determine the surface roughness. The base material of the implants is based on titanium (pure titanium or its alloys).

Table 1. Implants analysed

\begin{tabular}{|l|l|l|}
\hline No. & Type & Characteristics \\
\hline 1 & Nobel Active & Internal Regular Platforme $4.3 \times 13 \mathrm{~mm}$ \\
\hline 2 & Alpha-Bio & NeO $4.2 \times 13 \mathrm{~mm}$ \\
\hline 3 & Straumann-BL & Titanium SL Active Implant $4.1 \times 12 \mathrm{~mm}$ Bone level \\
\hline 4 & Zimmer TSV & Implant - MTX $4.1 \times 13 \mathrm{~mm}$ \\
\hline 5 & Dentium & Super Line $4.5 \times 12 \mathrm{~mm}$ \\
\hline 6 & Zimmer Pi & Implant AMP $4 \times 13 \mathrm{~mm}$ OSPOL \\
\hline 7 & Biomet 3i & Tapered implant T3 4/3×13 mm \\
\hline 8 & Biohorizons & $4.6 \times 12 \mathrm{~mm}$ \\
\hline 9 & IHDE & Hexacone $4.5 \times 11.5 \mathrm{~mm}$ OSMOACTIV \\
\hline 10 & KA Implant & $4.7 \times 8 \mathrm{~mm}$ \\
\hline 11 & Implant Ti6Al4V material & Internal Hex $3.75 \mathrm{~mm}$ platform, size $4.2 \times 10 \mathrm{~mm}$ \\
\hline 12 & Basic material for implants (Ti6Al4V) & Ti6Al4V, $16 \mathrm{~mm}$ diameter disc. \\
\hline
\end{tabular}

Surface roughness is the set of irregularities that make up the real surface relief and which are conventionally defined within the limits of a section without any shape deviations.

The method of determining the surface roughness is specified in ISO 4287, which also defines the parameters of the determinations. The scan length (run-off length) is the total length on which the probe moves on the piece during the scanning process.

The average of arithmetic roughness Ra was determined, respectively the height of the profile irregularities $\mathrm{Rz}$ in 10 points. $\mathrm{Ra}$ is the universally recognized and most widely used roughness parameter, representing the arithmetic mean of the absolute deviations of the roughness profile from the average line.

For determining the roughness was used a Profilometer Taylor-Hobson - Surtronic 25 (Figure 1).

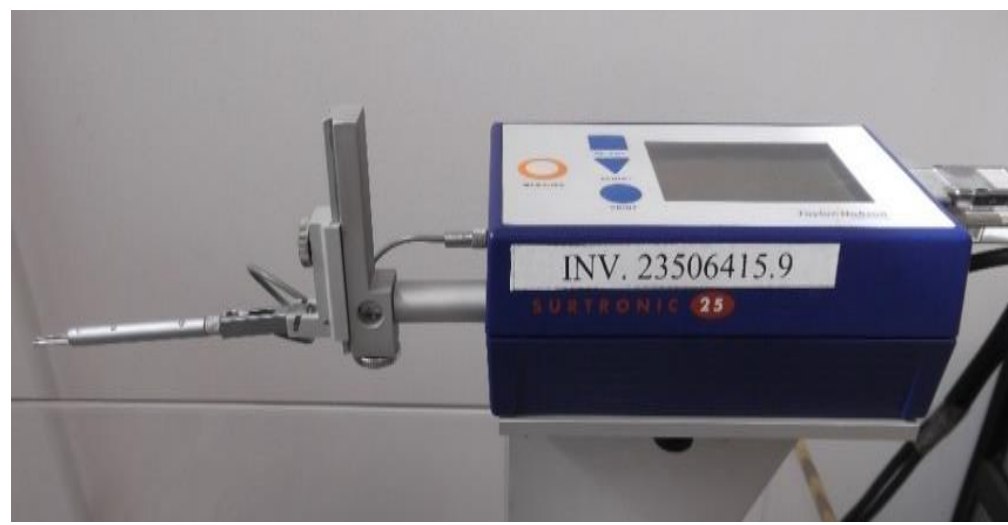

Fig. 1. Profilometer Taylor-Hobson - Surtronic 25

To make the determinations, the samples were fastened by means of a clamping device. For each individual sample, five roughness determinations were made, and the arithmetic mean of the obtained results was subsequently made.

The values obtained in the roughness measurements are presented in Table 2.

Table 3 shows the surface roughness of $\mathrm{Ti}_{6} \mathrm{Al}_{4} \mathrm{~V}$ samples.

Implants surface scanning was additionally performed using a MicroScratch Tester device, the sensing head having Rockwell geometry, made of 100Cr6 steel (shown in Figure 2). 
RECENT, Vol. 19, no. 1(54), 2018

Table 2. Roughness values for studied implants

\begin{tabular}{|c|c|c|c|c|c|c|}
\hline \multirow{2}{*}{ Sample } & \multicolumn{2}{|c|}{ Roughness values } & \multicolumn{2}{|c|}{ Mean } & \multicolumn{2}{|c|}{ Statistic deviation } \\
\hline & $\operatorname{Ra}(\mu \mathrm{m})$ & $\mathrm{Rz}(\mu \mathrm{m})$ & $\operatorname{Ra}(\mu \mathrm{m})$ & $\mathrm{Rz}(\mu \mathrm{m})$ & $\mathrm{Ra}(\mu \mathrm{m})$ & $\mathrm{Rz}(\mu \mathrm{m})$ \\
\hline \multirow{3}{*}{1} & 1.6 & 10 & \multirow{3}{*}{1.6} & \multirow{3}{*}{11} & \multirow{3}{*}{0} & \multirow{3}{*}{1} \\
\hline & 1.6 & 12 & & & & \\
\hline & 1.6 & 11 & & & & \\
\hline \multirow{4}{*}{2} & 2.8 & 18 & \multirow{4}{*}{2.85} & \multirow{4}{*}{17.25} & \multirow{4}{*}{0.1} & \multirow{4}{*}{0.957427} \\
\hline & 2.8 & 18 & & & & \\
\hline & 3 & 16 & & & & \\
\hline & 2.8 & 17 & & & & \\
\hline \multirow{5}{*}{3} & 8.6 & 41 & \multirow{5}{*}{8.36} & \multirow{5}{*}{54.4} & \multirow{5}{*}{0.219089} & \multirow{5}{*}{7.635444} \\
\hline & 8.6 & 60 & & & & \\
\hline & 8.2 & 57 & & & & \\
\hline & 8.2 & 58 & & & & \\
\hline & 8.2 & 56 & & & & \\
\hline \multirow{4}{*}{4} & 8 & 58 & \multirow{4}{*}{7.95} & & & \\
\hline & 7.8 & 60 & & 50.75 & 01 & 1250206 \\
\hline & 8 & 60 & & 59.15 & 0.1 & 1.258306 \\
\hline & 8 & 61 & & & & \\
\hline & 1.2 & 10 & & & & \\
\hline 5 & 1 & 9 & 115 & 9.25 & 0.1 & 0957427 \\
\hline S & 1.2 & 10 & $1.1 \mathrm{~J}$ & 3.25 & 0.1 & לים \\
\hline & 1.2 & 8 & & & & \\
\hline & 15 & 55 & & & & \\
\hline 6 & 14.2 & 52 & 147 & 54 & 0.34641 & 1414 \\
\hline 6 & 14.8 & 54 & 14.7 & & 0.34641 & 1.414 \\
\hline & 14.8 & 55 & & & & \\
\hline & 6.6 & 46 & & & & \\
\hline & 7.6 & 54 & & & & \\
\hline 7 & 7.8 & 54 & 7.52 & 52.4 & 0.521536 & 3.646917 \\
\hline & 7.8 & 53 & & & & \\
\hline & 7.8 & 55 & & & & \\
\hline & 2.8 & 16 & & & & \\
\hline & 3 & 20 & & 1925 & 01 & 2217356 \\
\hline 8 & 3 & 20 & 2.95 & 19.25 & 0.1 & $2.21 / 356$ \\
\hline & 3 & 21 & & & & \\
\hline & 22 & 118 & & & & \\
\hline & 22.2 & 122 & & & & \\
\hline & 22.2 & 122 & & & & \\
\hline 9 & 22 & 121 & 21.91429 & 120.2857 & 0.254484 & 1.496026 \\
\hline & 21.8 & 120 & & & & \\
\hline & 21.6 & 119 & & & & \\
\hline & 21.6 & 120 & & & & \\
\hline & 10.2 & 72 & & & & \\
\hline & 9.6 & 72 & & & & \\
\hline 10 & 9.8 & 72 & 9.8 & 72.2 & 0.244949 & 0.447214 \\
\hline & 9.6 & 72 & & & & \\
\hline & 9.8 & 73 & & & & \\
\hline & 5.8 & 41 & & & & \\
\hline 11 & 5.8 & 39 & 5.8 & 40 & 0 & 1 \\
\hline & 5.8 & 40 & & & & \\
\hline
\end{tabular}

Table 3. The surface roughness of $\mathrm{Ti}_{6} \mathrm{Al}_{4} \mathrm{~V}$ samples

\begin{tabular}{|c|c|c|c|c|c|c|}
\hline \multicolumn{6}{|c|}{ Roughness $(\mu \mathrm{m})$} & Mean roughness $(\mu \mathrm{m})$ \\
\hline $\mathrm{Ra}$ & 0.6 & 0.6 & 0.6 & 0.4 & 1 & 0.64 \\
\hline $\mathrm{Rz}$ & 5 & 5 & 6 & 3 & 9 & 5.6 \\
\hline
\end{tabular}




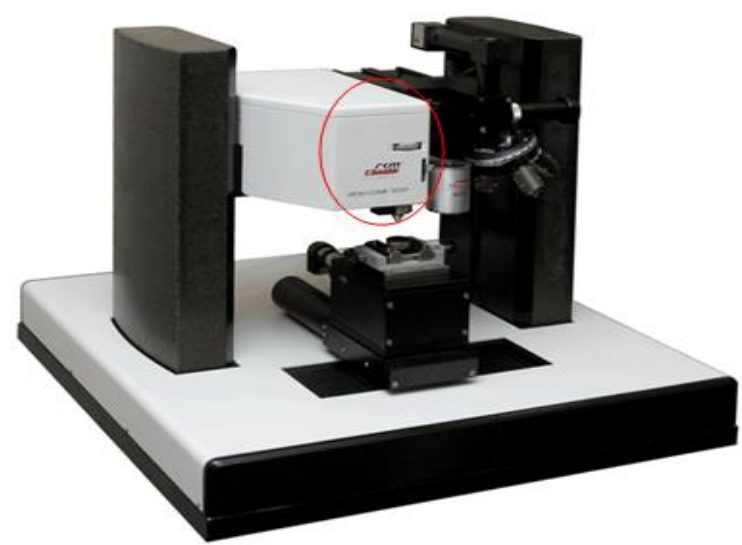

Fig. 2. Micro-scratch Tester

The parameters used for scanning are listed below:

- Constant load $0.03 \mathrm{~N}$

- Scanning speed $0.5 \mathrm{~mm} / \mathrm{min}$

- Scanning distance 0.5-1 mm, depending on the geometry of the analyzed sample.

The graphs generated by the equipment show the variation of the friction coefficient, friction force, penetration depth and surface profile for the scanned length. Due to the very low scanning force, variation in penetration depth can be considered to be representative of the surface profile.

The device is equipped with sensors that measure and record acoustic emissions, penetration depth and tangential force (to determine the friction coefficient) throughout the process.

\section{Results and Discussions}

The comparison of the results presented in Table 2 can be seen in Figure 3. It is observed the ordering of the Ra and Rz respectively for the analysed samples. It is noted that generally low values of roughness result in low friction coefficients for the scanned area, increasing with roughness.

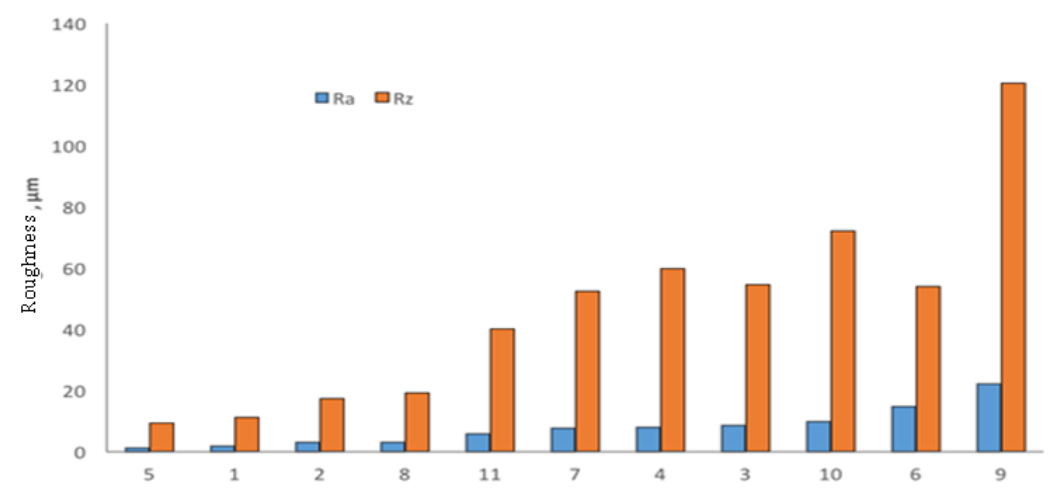

Fig. 3. The average values of the surface roughness, ordered in ascending order

Average roughness value Ra is $7.69 \mu \mathrm{m}$. In Figure 3 can be observed a series of samples showing low values of roughness (sample no. 1: $1.6 \mu \mathrm{m}$, sample no. 2: $1.15 \mu \mathrm{m}$ ), but also samples whose roughness is relatively high compared to the average of the measurements made (sample no. 9: 21.91 $\mu \mathrm{m}$, sample no. 6: $14.7 \mu \mathrm{m}$ ).

Regarding the height of the irregularities of the profile in ten points, it can be said that this value increases proportionally with the arithmetic average roughness value, so the sample with the maximum value of the roughness Ra corresponds to the maximum value of roughness Rz (sample no. 9: $\mathrm{Ra}=21.91 \mu \mathrm{m} ; \mathrm{Rz}=120.28 \mu \mathrm{m})$.

Figures 4 to 9 show some variations of the dynamic friction coefficient for the scanned area for representative samples. 
RECENT, Vol. 19, no. 1(54), 2018

Figure 10 shows the variation of the coefficient of friction for the representative samples.

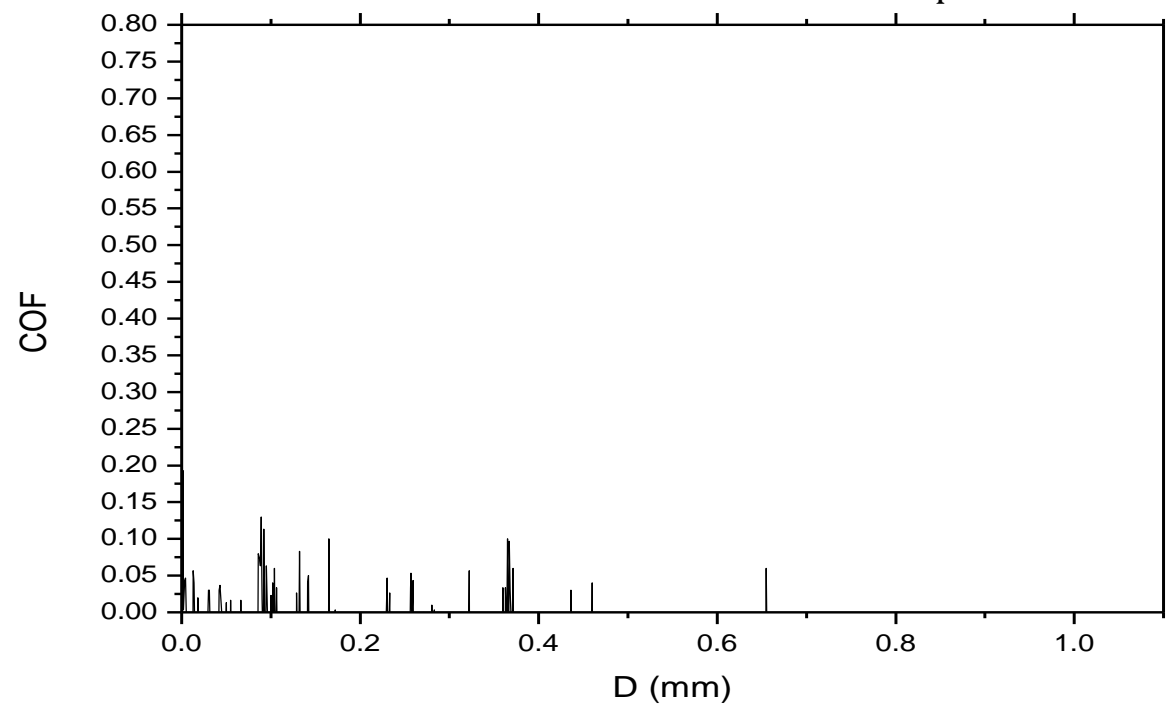

Fig. 4. Friction coefficient variation on scanned distance, for sample no. 1

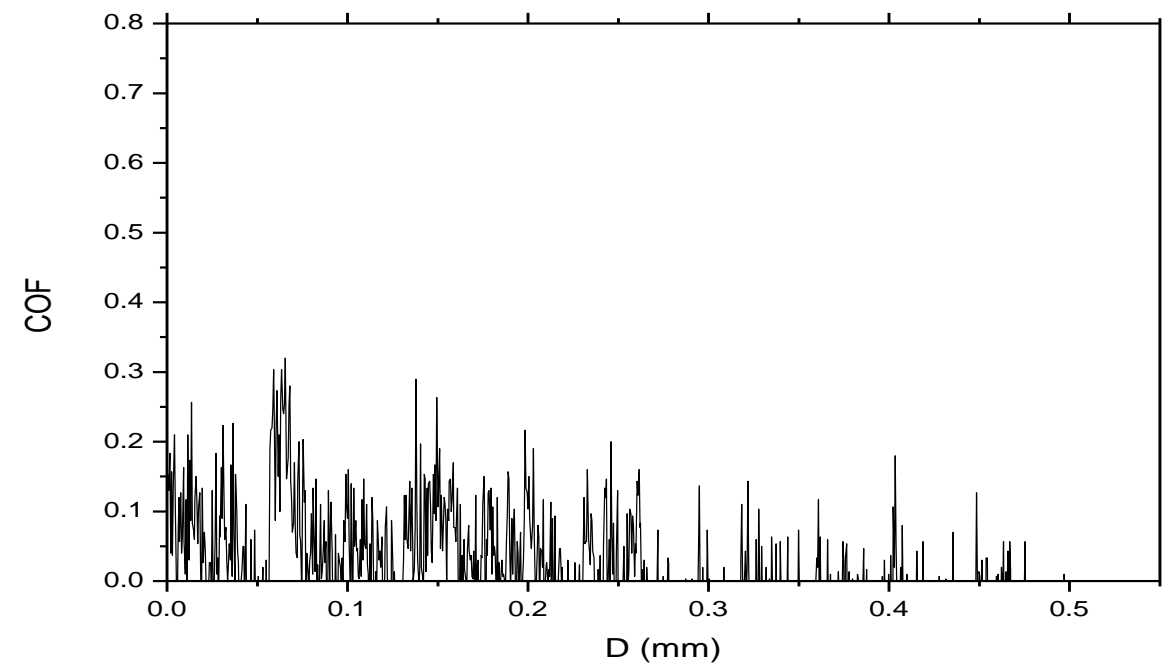

Fig. 5. Friction coefficient variation on scanned distance, for sample no. 2

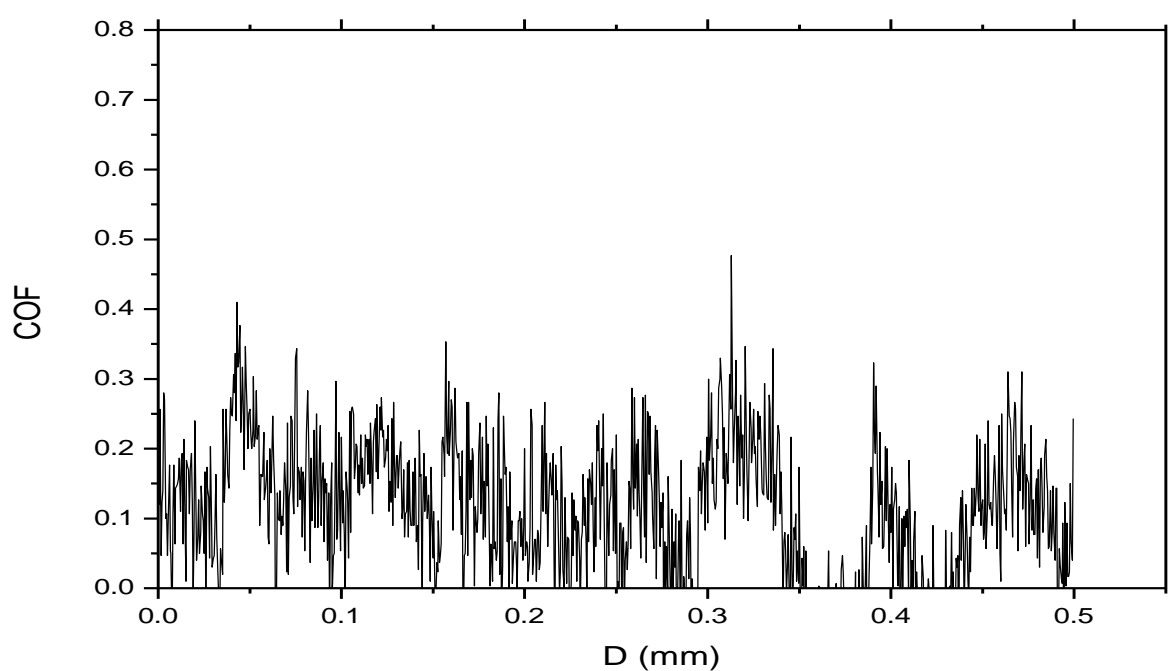

Fig. 6. Friction coefficient variation on scanned distance, for sample no. 8 


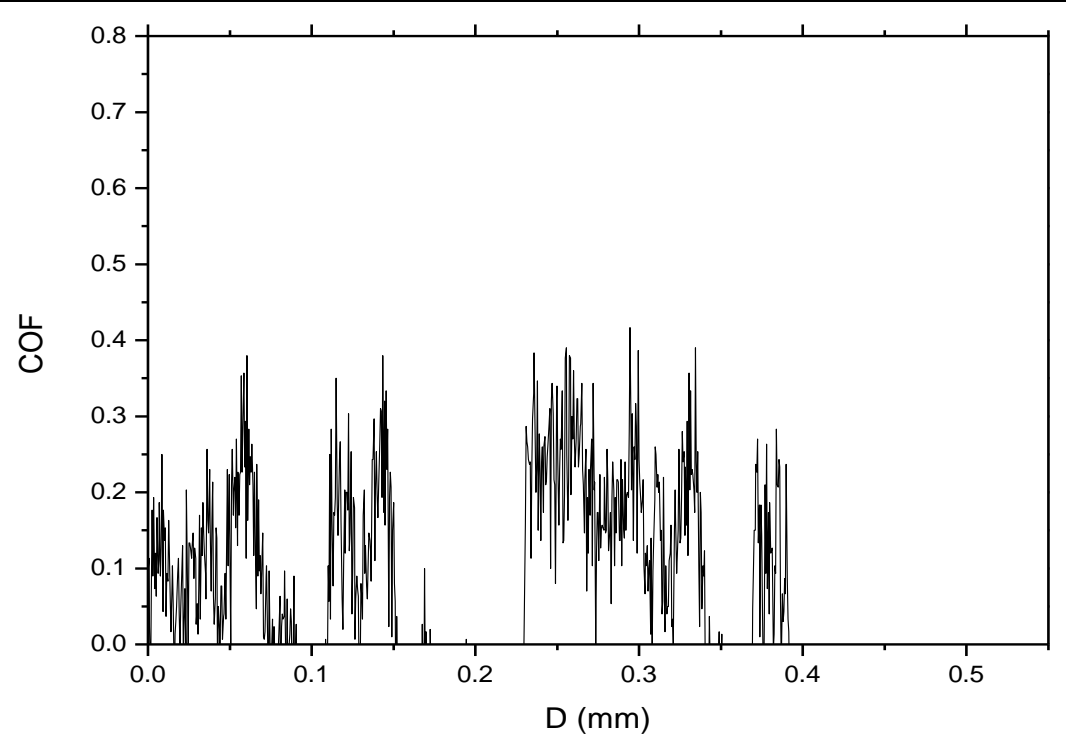

Fig. 7. Friction coefficient variation on scanned distance, for sample no. 3

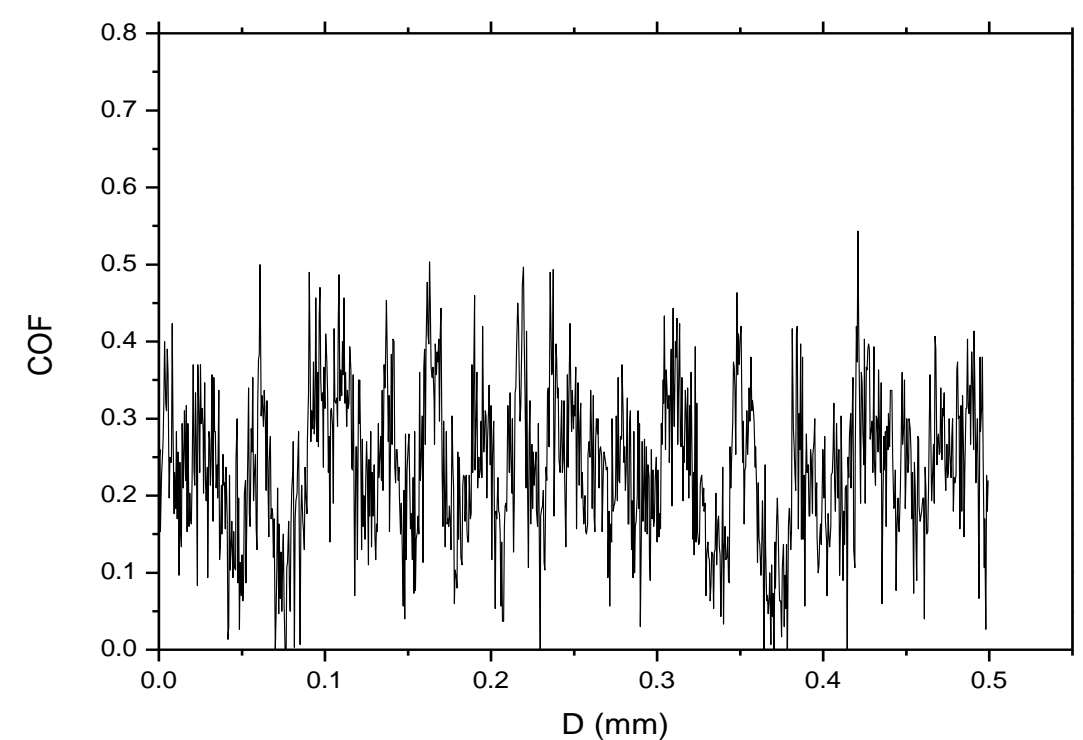

Fig. 8. Friction coefficient variation on scanned distance, for sample no. 10

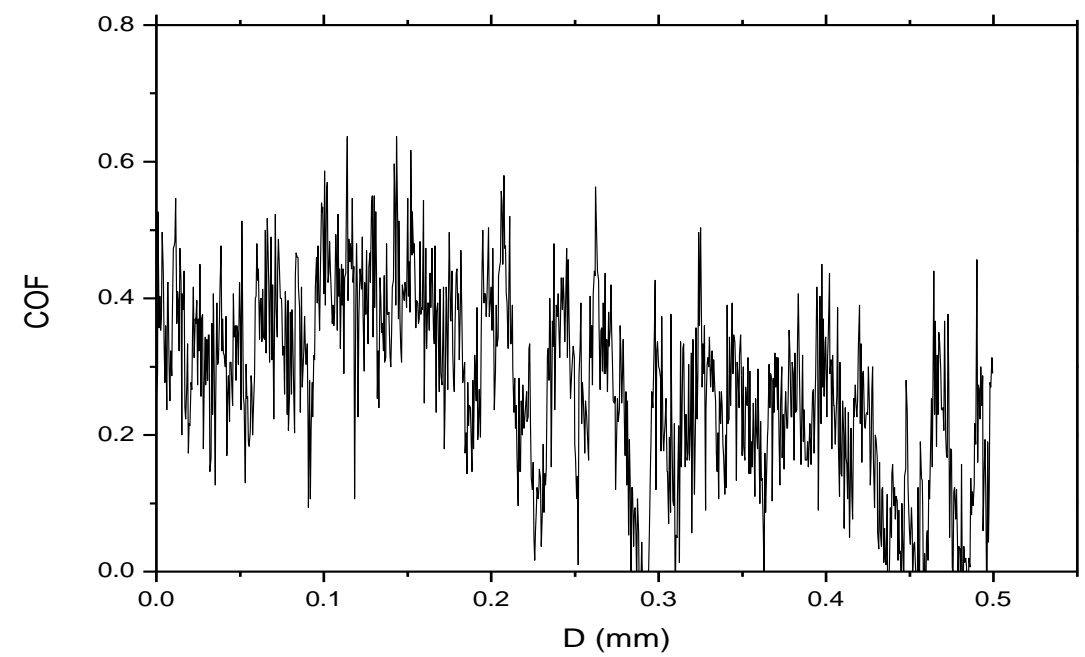

Fig. 9. Friction coefficient variation on scanned distance, for sample no. 9 


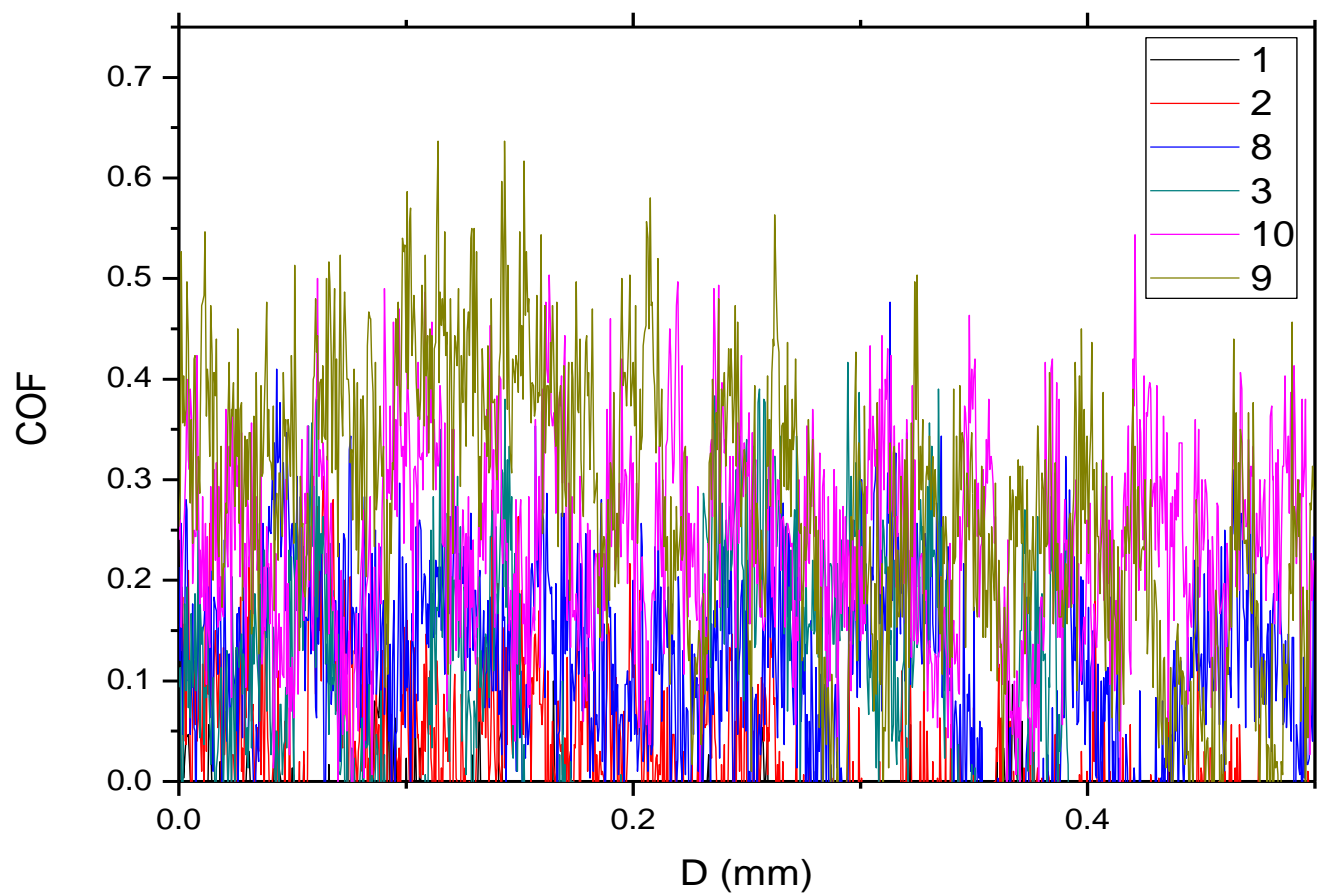

Fig. 10. Comparison of variance of friction coefficient for representative samples

In order to highlight how the dynamic friction coefficient varied during wear tests for $\mathrm{Ti}_{6} \mathrm{Al}_{4} \mathrm{~V}$, Table 4 shows the starting values (static friction coefficient) as well as the minimum, maximum and average values of the dynamic friction coefficients, recorded during the test.

Table 4. The values of the friction coefficients for $\mathrm{Ti}_{6} \mathrm{Al}_{4} \mathrm{~V}$ and for the implant no. 11

\begin{tabular}{|c|c|c|c|c|c|}
\hline \multirow{2}{*}{ Test no. } & \multicolumn{5}{|c|}{ Friction coefficients } \\
\cline { 2 - 5 } & $\mu_{\text {start }}$ & $\mu_{\min }$ & $\mu_{\max }$ & $\mu_{\text {mean }}$ & Deviation \\
\hline \multicolumn{7}{|c|}{$\mathbf{T i}_{6} \mathbf{A l}_{\mathbf{4}} \mathbf{V}$} \\
\hline $\mathbf{1}$ & 0.292 & 0.292 & 0.524 & 0.455 & 0.036 \\
\hline $\mathbf{2}$ & 0.352 & 0.322 & 0.493 & 0.418 & 0.032 \\
\hline $\mathbf{3}$ & 0.407 & 0.369 & 0.533 & 0.460 & 0.040 \\
\hline $\mathbf{4}$ & 0.206 & 0.201 & 0.451 & 0.392 & 0.033 \\
\hline $\mathbf{5}$ & 0.246 & 0.246 & 0.499 & 0.422 & 0.039 \\
\hline $\mathbf{1}$ & 0.175 & 0.168 & 0.794 & 0.583 & 0.067 \\
\hline $\mathbf{2}$ & 0.244 & 0.232 & 0.924 & 0.626 & 0.120 \\
\hline $\mathbf{3}$ & 0.203 & 0.196 & 0.822 & 0.563 & 0.083 \\
\hline
\end{tabular}

\section{Conclusion}

The following conclusions can be drawn from the performed analyses:

- Average roughness ranges from $\sim 0.05$ for sample no. 1 to mean $\sim 0.3$ for sample no. 9;

- The maximum roughness value is six times the minimum;

- For all the samples it was observed that the friction coefficient vary over a wide range of values along the scanned distance. As expected, the sample (sample no. 9) with the highest roughness value $(21.91 \mu \mathrm{m})$ presents also the highest start value of the friction coefficient (around 0.4) and a relatively high medium value, around 0.3. Samples no. 2 and no. 8 presents lower friction coefficient values relative to the other analysed samples. However, the lowest value for both roughness and friction coefficient was measured for sample no. 1. Thus, this sample presents a friction coefficient below 0.1 , in concordance with the roughness value $(1.6 \mu \mathrm{m})$; 
- A connection between surface roughness and friction / wear behaviour has been observed so that a high friction coefficient is also characterized by a high roughness of the surface and a variation of the low friction coefficient is also characterized by a low roughness;

- Although these mean values fall under the requirements of osteointegration, there are large differences between the average values of roughness.

The distribution of the results requires a detailed study of the real effects of roughness on osteointegration of dental implants. The very large differences between the roughnesses of different brands of dental implants suggest that some manufacturers either do not pay attention to this detail in terms of surface morphology, or consider the roughness of their product more appropriate. Clinical studies demonstrating which values of roughness are more beneficial to osteointegration require considerable human and material time and effort; for this reason, not all manufacturers have published similar studies.

\section{Acknowledgement}

We hereby acknowledge the project "Innovative method for functional dental implant surfaces to improve osteointegration", MySMIS 104809, ANCSI 73/8.09.2016.

This article is a part of the result within the Research Contract no. 84/01.09.2017 signed between Dentix Millennium SRL and the ICDT Institute of Transilvania University of Brasov

\section{References}

1. Shemtov-Yona K., Rittel D. (2015): An overview of the mechanical integrity of dental implants. BioMed Research International, e-ISSN 2314-6141, http://dx.doi.org/10.1155/2015/547384

2. Asaoka K, Kuwayama N, Okuno O, Miura I. (1985): Mechanical properties and biomechanical compatibility of porous titanium for dental implants. J Biomed Mater Res., ISSN 1552-4965, 19(6), p. 699-713, DOI: 10.1002/jbm.820190609

3. Rosa M.B., Albrektsson T., Francischone C.E., Schwartz Filho H.O., Wennerberg A. (2012): The influence of surface treatment on the implant roughness pattern. J Appl. Oral Sci., v.20(5), p. 550555, DOI: 10.1590/S1678-77572012000500010

4. Wennerberg A., Albrektsson T. (2000): Suggested guidelines for the topographic evaluation of implant surfaces. Int. J Oral Maxillofac. Implants, e-ISSN 1942-4434, 15(3), p. 331-344, https://pdfs.semanticscholar.org/bf01/f2af7c4262813e91f226608c1fc40ee1e8e6.pdf 